\title{
Scientific publication-a cornerstone of the research cycle
}

The publication of new scientific findings in the form of original papers in scientific journals is a cornerstone of the research process. Such publication not only presents the findings to the rest of the scientific world, it establishes the reputation of the researcher, encourages others to join him or her and to pursue the next stage, and is crucial to the researcher's efforts to obtain financial and other support for the work and to the overall standing of the institution in which the work is done. Thus, all who are part of this process of scientific publication bear a heavy responsibility for fairness, impartiality and integrity. The Journal of Medical Microbiology has been playing its part in this process for 25 years as an independent publication, and before 1968 as the Journal of Pathology and Bacteriology, a title that reflected the scientific interests of the Pathological Society of Great Britain and Ireland in matters across the full range of pathology and microbiology in relation to human and veterinary medicine.

J. G. Collee, who was a founding editor of the Journal, chairman of the editorial board until 1988 and a senior editor until 1991, outlines the myriad developments in medical microbiology during his career spanning some four decades on pp. 87-91.

In parallel with the almost exponential growth of the subject since 1968, the Journal grew from a quarterly publication presenting 50-60 papers each year to a monthly one of international repute with 140-150 papers including editorials and reviews on topics of current interest and representing contributions from countries around the world. The contents lists over the years reflect all the microbiological developments of that period, from the emergence of plasmid-mediated antibiotic resistance in the 1960 s to the use of the polymerase chain reaction for diagnosis of opportunist mycobacterial infection in AIDS patients in the 1990s. There have been recurrent themes - the widening range of pathogenicity of staphylococci, the epidemiology of salmonellae and the growing awareness of non-sporing anaerobes (a consistent interest of successive editors)-and there have been new organisms and their diseasesClostridium difficile and antibiotic-associated diarrhoea, Campylobacter spp. and enteritis, Legionella pneumophila and pneumonia, HIV and AIDS; these provide the core material for the Journal. For interest, the title page and contents page of the first issue are reproduced at the beginning of this issue.

However, although there is no journal without the raw material of the original research papers, it is equally true that this material could not see the light of day without the colleagues who have formed the editorial boards of the Journal throughout the 25 years: the chairmen of the board who have guided and managed the Journal's affairs; the senior editors who have been responsible for overall production matters (idiosyncratically given the title sureditor); rejection editors who have given courteous and, we hope, constructive rejection reports (and often rehabilitated papers with a nugget of scientific interest initially obscured and confused by imprecise language or overelaboration); the editorial and review editors; and of particular importance, the members of the editorial board who in the first place handle the submitted papers. The authors whose papers have appeared in the Journal have benefitted greatly from the work of these colleagues-who are all themselves drawn from the same medical and scientific research community and do their editorial work, unpaid and generally unsung, because of their interest in their science.

\section{The research and publication process}

Scientific research is a continuous process (represented by the figure) but the starting point is a hypothesis that can be tested by laboratory experimentation or epidemiological or clinical investigation. The data generated, which either support or refute the hypothesis, are collated, analysed and interpreted in the form of a manuscript that is submitted to a scientific journal for publication.

The publication process. With this Journal, the manuscript is assigned by the sureditor to a member of the editorial board with particular interest and expertise in the field for the peer-review process. The editor may accept an obviously good paper without referral, but cannot reject without further review. A second, and sometimes a third, view is generally sought from an expert referee and the editor then decides between acceptance, revision or rejection. Papers for rejection are channelled through a rejection editor, who reviews the manuscript a final time (and sometimes rescues it for rehabilitation) and returns it to the author with as much helpful comment as possible. Acceptable manuscripts are edited initially by the assigned editor, in correspondence with the author, and then passed to the sureditor, who co-ordinates the technical editorial mark-up, the lettering and presentation of the figures, and the final detailed editing to achieve the high standard of presentation of which the Journal is proud. The manuscript then passes into the production chain for typesetting and generation of proofs. At proof, each paper is sent for checking to the 


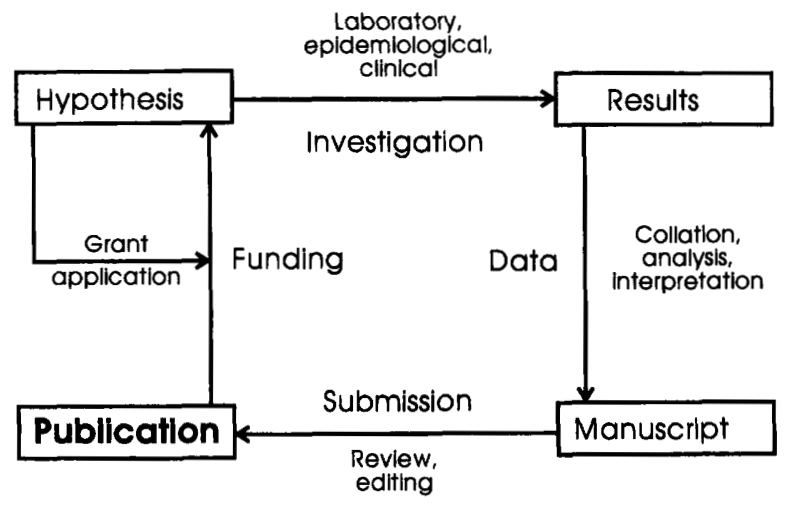

Figure. The research cycle.

author, the assigned editor and to a second editor, and then proof-read and the corrections collated by our proof-reader-all essential steps in ensuring reliable and accurate publication. The corrections are checked again by our proof-reader after revision by the printers, and the final version is passed for press. Each stage is necessary to ensure the quality of the final product, which itself can be the launch-pad for further work.

Funding scientific research. One of the key factors in maintaining a research programme is sustained funding through research grants from governmental or charitable sources. This in itself depends to a large extent upon the proven record of the researcher, the evidence for which lies in the publications generated by his or her previous work-the performance indices represented by the number of publications, the standing and reputation of the journals in which they appear, and the citation index of the papers. In this way, the cornerstone of publication completes the cycle representing the research process.

\section{The publication dilemmas}

The pivotal role of publication in research activity highlights two dilemmas of our publication system in a cost-limited and performance-indexed environment. The economics of journal publication depend, on the one hand, upon the professional input of the editors at minimal cost and, on the other, upon the need of researchers to read the current "literature" and, therefore, for them to purchase personal copies of journals and for the libraries of research institutions to have institutional subscriptions. With pressure for economies in libraries, in particular, the number of subscriptions is reduced. This not only deprives researchers, especially the young ones, of the opportunity to read a wide range of journals, it also threatens the financial viability of the journals themselves. Even if more individuals take out subscriptions, these are generally through arrangements (e.g., Pathological Society membership in our case) that barely cover costs and do not contribute to the journal's overall profitability, which is essential for it to be attractive to publishers. Again, the scientific societies subsidise their other activities, equally vital to scientific life, from the profits of their publishing activities. Without the accessibility of journals, fewer papers can be published and reach a wide readership, interrupting the research cycle and threatening potential opportunities for future research. Thus, funds withdrawn from an institution's library subscriptions reduce the opportunity for that institution's researchers to publish their findings.

Similar pressures are brought to bear on editors who are themselves active scientists. The time required to review and edit papers is considerable, and there is little financial reward for either the individual or his or her institution. With the pressure to provide value for money, such "non-profitable" work is frowned upon and this professional activity may be regarded as unacceptable during the normal working day when it is thought to detract from the primary responsibility to clinical and diagnostic duties, teaching and research. Thus, the institution may seek to restrict an editor's involvement in an activity on which it depends for the dissemination of its research product and for an index of its performance. It is to the credit of those editors who still maintain the balance of commitment to their own research and service activity with their editorial contribution.

\section{Look to the future}

If the future of healthy research depends upon a healthy scientific press for dissemination of its findings, the future of a peer-reviewed publication system has to be sustained. At present, this remains heavily embedded in the traditional approach of submission of a typescript, editorial work in longhand on the typescript, typesetting, proof correction and finally printing, binding and distribution as hard copy. Nevertheless, the computer technology that is driving so much of our research is also widening the scope for dissemination of the results. Submission of articles on disk is only the first small step. It would be feasible for authors to present their material directly into a database accessible by a common network, but that is clearly unacceptable in its simplest form; it takes no account of peer review and editorial rigour in ensuring that published material is of an acceptable standard or of the need for categorisation and indexing of material to make it accessible to those at whom it is directed. The new technology has much to offer, but the structure and function of a journal will still be necessary whatever the output medium.

The last 25 years have seen many advances in the science of medical microbiology, and the editorial team of the Journal of Medical Microbiology is proud of its contribution to that process. Whatever technological changes bring, we trust that the basic role of the Journal in completing the cycle of scientific research will be sustained during the next 25 years.

B. I. DUERDEN Chairman and sureditor. 